\title{
Analgesic, Anti-Inflammatory and Anticancer Activities of Extra Virgin Olive Oil
}

\author{
Myriam Fezai, ${ }^{1}$ Laura Senovilla, ${ }^{2,3}$ Mohamed Jemaà, ${ }^{2,3,4}$ and Mossadok Ben-Attia ${ }^{1}$ \\ ${ }^{1}$ Laboratoire de Biosurveillance de l'Environnement (LR01/ES14), Equipe REMP "Risque Écologique des Médicaments \& Pesticides", \\ Faculté des Sciences de Bizerte, Université de Carthage, 7021 Zarzouna, Tunisia \\ ${ }^{2}$ INSERM, U848, 94805 Villejuif, France \\ ${ }^{3}$ Institut Gustave Roussy, 94805 Villejuif, France \\ ${ }^{4}$ CNRS UMR5237, CRBM 1919 Route de Mende, 34293 Montpellier, France
}

Correspondence should be addressed to Mohamed Jemaà; jemaamohamed@gmail.com and Mossadok Ben-Attia; benattia.mossa@gmail.com

Received 20 May 2013; Revised 10 October 2013; Accepted 24 October 2013

Academic Editor: Maurizio Averna

Copyright (C) 2013 Myriam Fezai et al. This is an open access article distributed under the Creative Commons Attribution License, which permits unrestricted use, distribution, and reproduction in any medium, provided the original work is properly cited.

\begin{abstract}
Background. In folk medicine, extra virgin olive oil (EVOO) is used as a remedy for a variety of diseases. This study investigates the in vivo antinociceptive, anti-inflammatory, and anti-cancer effects of EVOO on mice and rats. Materials and Methods. In this experimental study, using the acetic acid-induced writhing and formalin tests in mice, the analgesic effect of EVOO was evaluated. Acetylsalicylic acid and morphine were used as standard drugs, respectively. The anti-inflammatory activity was investigated by means of the carrageenan-induced paw edema model in rats using acetylsalicylic acid and dexamethasone as standard drugs. Last, the xenograft model in athymic mice was used to evaluate the anticancer effect in vivo. Results. EVOO significantly decreased acetic acid-induced abdominal writhes and reduces acute and inflammatory pain in the two phases of the formalin test. It has also a better effect than Dexamethasone in the anti-inflammatory test. Finally, the intraperitoneal administration of EVOO affects the growth of HCT 116 tumours xenografted in athymic mice. Conclusion. EVOO has a significant analgesic, anti-inflammatory, and anticancer properties. However, further detailed studies are required to determine the active component responsible for these effects and mechanism pathway.
\end{abstract}

\section{Introduction}

The Mediterranean diet rich in nuts, fruits, vegetables, legumes, whole-wheat bread, fish, and olive oil [1] has a wellestablished beneficial role in health promotion [2]. Virgin olive oil is an integral ingredient of this traditional diet and for centuries Mediterranean people have appreciated his nutritional, medical, and cosmetics benefits [3]. Indeed, virgin olive oil has been used as a folk remedy for combating diseases due to its pharmacological properties including cardioprotective, hypotensive, antihyperglycemic, antimicrobial, and antiinflammatory effects [4-7]. Nowadays, epidemiological studies on virgin olive oil consumers reveal an important decrease in chronic disease, that is, cardiovascular diseases (CVD) [8], atherosclerosis [9], and some types of cancers especially colorectal and breast cancer [10]. In addition, Mediterranean people show a higher life expectancy compared with olive oil consume less populations worldwide [11]. Virgin olive oil is the oil obtained from the fruit of the olive tree solely by mechanical or physical means (the cold-pressed technique), which do not lead to alterations of the oil. Based on the acidity, the International Olive Oil Council has defined the classification of virgin olive oil as follows: extra virgin olive oil, virgin olive oil, and ordinary virgin olive oil. Thus, oil retains the compounds that the fruit develops in response to environmental stress and especially phenolic compounds [12].

In this study, we decided to focalize on the extra virgin olive oil (EVOO) and to investigate its antinociceptive, antiinflammatory, and anticancer effects using in vivo experimental models, namely, the acetic acid-induced abdominal writhing test as well as formalin test to assess the analgesic 
activity, the carrageenan-induced hindpaw edema model for the anti-inflammatory activity, and human colon carcinoma cells xenograft in nude mice to evaluate the anticancer effect.

\section{Materials and Methods}

2.1. Chemicals. Extra virgin olive oil (Carapelli, Extra Virgin Olive Oil, Florence, Italy) was purchased from local market. PBS was purchased from Gibco-Invitrogen (Carlsbad, CA, USA). Formalin (formaldehyde stock solution 4\% (w/v)) was purchased from Sigma-Aldrich (St Louis, MO, USA) while carrageenin (fresh-prepared) and acetic acid (stock solution at $60.05 \mathrm{mM}$ ) were provided from Sigma-Aldrich (Taufkirchen, Germany). Dexamethasone sodium phosphate ( $0.4 \%$ injectable solution) had been supplied from Medis laboratories (Nabeul, Tunisia), Aspirin Acetylsalicylic Acid $(10 \%(\mathrm{w} / \mathrm{v})$ injectable-solution) from (LABESFAL, Laboratorios Almiro, Campo de Besteiros, Portugal) and Morphine Chlorhydrate (1\% injectable-solution) purchased from Renaudin Laboratories (Itxassou, France). All the drugs were dissolved in saline. Standard solution imbibante BBC97 (Chimifoto Ornano, Italy) was used for plethysmometer (model 7150, Ugo Basile, Italy).

2.2. Cell Lines. Wild type human colon carcinoma HCT 116 cells (kindly provided by Bert Vogelstein, The Ludwig Center for Cancer Genetics and Therapeutics and The Howard Hughes Medical Institute, Johns Hopkins Kimmel Cancer Center, Baltimore, MD, USA) were maintained in McCoy's $5 \mathrm{~A}$ medium supplemented with $10 \%$ fetal calf serum (FCS), $10 \mathrm{mM}$ HEPES buffer, 100 units/mL penicillin $\mathrm{G}$ sodium, and $100 \mu \mathrm{g} / \mathrm{mL}$ streptomycin sulfate.

2.3. Animals. Albino Wistar female rats weighting (200 $\mathrm{g} \pm$ $20 \mathrm{~g}$ ) and albino Swiss male mice with $25 \mathrm{~g}$ and $30 \mathrm{~g}$ weight ranges, provided by the Pasteur Institute of Tunis, Tunisia, were used for the anti-inflammatory and analgesic activities in this study. Mice and rats were housed in laboratory transparent-plastic cages EBECO (groups of six/cage each). Athymic $n u / n u$ female mice (20-25g), provided by the Institut Gustave Roussy, Villejuif, France, in-house animal facility were used for the xenograft model throughout this study. Mice were kept in Makrolons type III wire mesh laboratory cages (Charles River, Boston, MA, USA). Animals were manipulated in strict compliance with widely accepted ethical guidelines for animal experimentation and kept under poor germ conditions at $24^{\circ} \mathrm{C}$ and $50-60 \%$ humidity and were allowed for food and water ad libitum prior to the experiments. Light cycle was artificially controlled to provide $14 \mathrm{~h}$ of light (from 06:30 a.m. to 08:30 p.m.).

\subsection{Analgesic Activity}

2.4.1. Acetic-Acid Writhing Test. The abdominal writhing response in mice to intraperitoneal injection of acetic acid was used as one of the well-established basic tests for analgesic activity [13]. Extra virgin olive oil was injected at $8 \mathrm{~mL} / \mathrm{kg}$ and Aspirin (acetylsalicylic acid) at $3.2 \mathrm{~g} / \mathrm{kg}$ was administered intraperitoneally (i.p.) $30 \mathrm{~min}$ prior to the acetic acid i.p. injection of $1 \%(\mathrm{v} / \mathrm{v})$ at a dose of $10 \mathrm{~mL} / \mathrm{kg}$ body weight. Acetylsalicylic acid (ASA) served as a positive control while the negative control animals received a similar volume of saline solution $0.9 \%$. All injection volumes are equal to $200 \mu \mathrm{L}$. Groups of 8 mice were placed in transparent boxes during the test and counting of abdominal constrictions started immediately after injection of acetic acid for $30 \mathrm{~min}$. The mice with decreased number of writhes were considered protected. Writhing count permitted the percentage of antinociceptive activity to be expressed according to the following ratio: percent inhibition $=\left(1-W_{t} / W_{c}\right) \times 100$, where $W_{t}$ and $W_{c}$ represent the number of writhing movements, measured between the treated and control groups.

2.4.2. Formalin Test in Mice. The formalin-induced nociception test was performed as described previously by Hunskaar and Hole [14] and recently by Nakamoto et al. [15]. Mice were divided into groups of 5 and were injected with $20 \mu \mathrm{L}$ of $10 \%$ formalin into the subplantar space of the left hind paw $30 \mathrm{~min}$ after olive oil pretreatment at crescent doses of $0.33 \mathrm{~mL} / \mathrm{kg}$, $0.66 \mathrm{~mL} / \mathrm{kg}, 1 \mathrm{~mL} / \mathrm{kg}$, and $1.33 \mathrm{~mL} / \mathrm{kg}$ corresponding, respectively, to $10 \mu \mathrm{L}, 20 \mu \mathrm{L}, 30 \mu \mathrm{L}$, and $40 \mu \mathrm{L}$. Morphine at a dose of $10 \mathrm{mg} / \mathrm{kg}$ was served as a positive control. Mice were observed through glass cages one by one and the time spent in liking, biting, and shaking behaviors was measured in seconds during the early phase $(0-5 \mathrm{~min})$ and late phase (5$30 \mathrm{~min})$.

\subsection{Anti-Inflammatory Activity}

2.5.1. Carrageenin-Induced Rat Paw Edema. The anti-inflammatory activity was evaluated using in vivo carrageenininduced rat paw edema model considered as the most conventional test for acute inflammation [16]. Wistar rats were divided into 6 groups, 6 rats each, and were injected into the subplantar space of the left hind paw with $200 \mathrm{mg} / \mathrm{kg}$ of ASA and $2 \mathrm{mg} / \mathrm{kg}$ of dexamethasone, as positive controls, and normal saline for negative one. Each rat received a subplantar injection of $100 \mu \mathrm{L}$. Extra virgin olive oil was administered at decreasing volumes of $100 \mu \mathrm{L}, 50 \mu \mathrm{L}$ and $25 \mu \mathrm{L}$ corresponding to $0.5 \mathrm{~mL} / \mathrm{kg}, 0.25 \mathrm{~mL} / \mathrm{kg}$, and $0.125 \mathrm{~mL} / \mathrm{kg}$. Edema was induced on the left hind paw of the rat by subplantar injection of $100 \mu \mathrm{L}$ of a solution of $0.6 \%(\mathrm{w} / \mathrm{v})$ carrageenan. Paw thickness was measured before and after carrageenan injection during 5 hours, using a plethysmometer. Percentile edema inhibition was calculated according to the following formula: percentile inhibition = $\left(1-V_{t} / V_{c}\right) \times 100$, where $V_{t}$ and $V_{c}$ represent the mean difference in paw measurement between the treated and control groups.

2.5.2. In Vivo Xenograft Models. Athymic nu/nu six-weekold female mice (IGR animal facility) were inoculated s.c. in $200 \mu \mathrm{L}$ of PBS with $2 \times 10^{6}$ HCT116 cells into the lower flank [17]. As soon as tumors reached $125 \mathrm{~mm}^{3}$, mice received i.p. $200 \mu \mathrm{L}$ of PBS $1 \mathrm{X}$ or extra virgin olive oil $(8 \mathrm{~mL} / \mathrm{kg})$ three times a week during 4 weeks. Tumor growth was evaluated 


\begin{tabular}{lcc} 
Agent & $\begin{array}{c}\text { Number of writhing } \\
\text { movements }\end{array}$ \\
\hline Control (saline) & 134.5 & \pm 17 \\
\hline Acetylsalicylic acid (ASA) & 63.5 & \pm 5.5 \\
\hline Extra virgin olive oil (EVOO) & 55.9 & \pm 18.3 \\
\hline
\end{tabular}

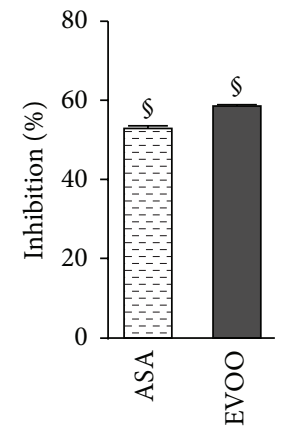

(a)

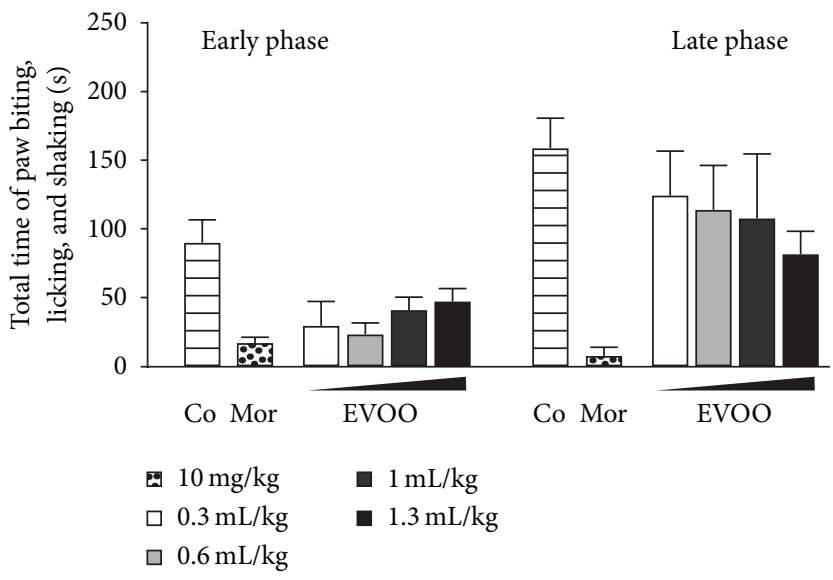

(b)

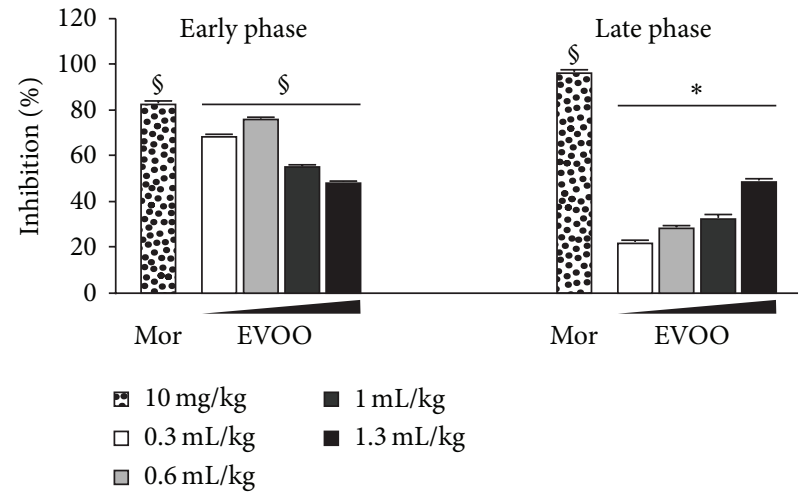

(c)

FIGURE 1: Antinociceptive effect of extra virgin olive oil. (a) Effect of intraperitoneal administration of acetylsalicylic acid (3.2 g/kg) and extra virgin olive oil ( $8 \mathrm{~mL} / \mathrm{kg})$ on acetic acid-induced Writhing. (b) Effect of intraplantar injection of morphine (10 mg/kg) and extra virgin olive oil (resp. $0.33,0.66,1$, and $1.33 \mathrm{~mL} / \mathrm{kg}$ ) on formalin-Induced nociceptive behavior in mice at early and late phase. acetylsalicylic acid and morphine used as reference agents. (c) Percentage of formalin-induced nociceptive inhibition by extra virgin olive oil and reference agents as compared to saline-treated mice. Results are reported as means \pm SD. ${ }^{*} P<0.05$ and ${ }^{\S} P<0.001$ (two-tailed Student's $t$-test), as compared to saline-treated mice.

twice a week using a caliper. The mean of the tumor volume at each point was normalized in each group to the mean volume measured at the first injection. All animals were maintained in specific pathogen-free conditions and all experiments followed the FELASA guidelines.

2.5.3. Statistical Analysis. All data are expressed as the mean \pm SD. The statistical significance of differences between controls and test values was assessed with Student's $t$-test (two tailed). Differences were considered significant if $P<0.05$.

\section{Results}

3.1. Analgesic Activity of Extra Virgin Olive Oil. The antinociceptive effect of extra virgin olive oil (EVOO) was assessed via two experimental models of chemical pain stimuli namely, Writhing test and Formalin test. The writhing test showed that the abdominal constriction responses, defined in writhing movements induced by intraperitoneal injection of acetic acid, were significantly decreased in pretreated mice. The EVOO (58\%) gives slightly better effect than acetylsalicylic acid (ASA) (52\%) compared with the control group for, respectively, $8 \mathrm{~mL} / \mathrm{kg}$ and $200 \mathrm{mg} / \mathrm{kg}$ (Figure 1(a)). ASA served as the antinociceptive standard drug in this assay. Concerning the Formalin test, the EVOO significantly reduced the nociception response for the intraplantar injection of $10 \%$ formalin inducing licking, biting, and shaking paw (Figure 1(b)). In both nontreated (naive) and pretreated mice, the formalin produces a biphasic period of intensive response which arises from 0 to $5 \mathrm{~min}$ after formalin injection that corresponds to the early phase, whereas the late phase was evident from 5 to $30 \mathrm{~min}$ with an intensive response during the last $10 \mathrm{~min}$. In the early phase, EVOO at a dose of $0.6 \mathrm{~mL} / \mathrm{kg}$ seems to be almost as potent as morphine at $10 \mathrm{mg} / \mathrm{kg}$, reference drug used in this test, with $76 \%$ against $82 \%$ of licking/biting inhibition, respectively. At late phase, the effect of EVOO is less efficient than the positive control morphine but still significantly antinociceptive in a dose dependent manner and the maximal effect was observed at $1.3 \mathrm{~mL} / \mathrm{kg}$ with $50 \%$ of licking/biting inhibition (Figure 1(c)).

3.2. Anti-Inflammatory Effect of Extra Virgin Olive Oil. We opted for the Carrageenan-induced paw edema model in rats, to evaluate the anti-inflammatory activity, as one of 


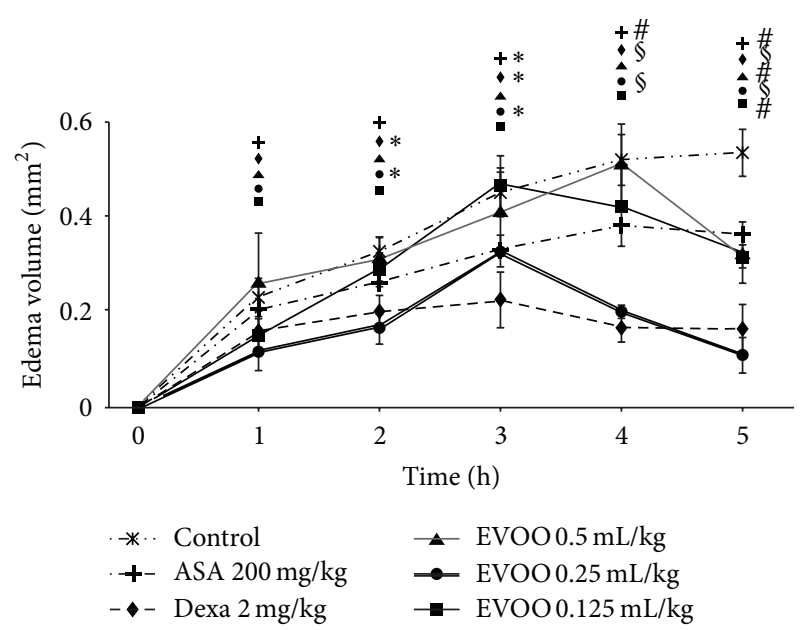

(a)

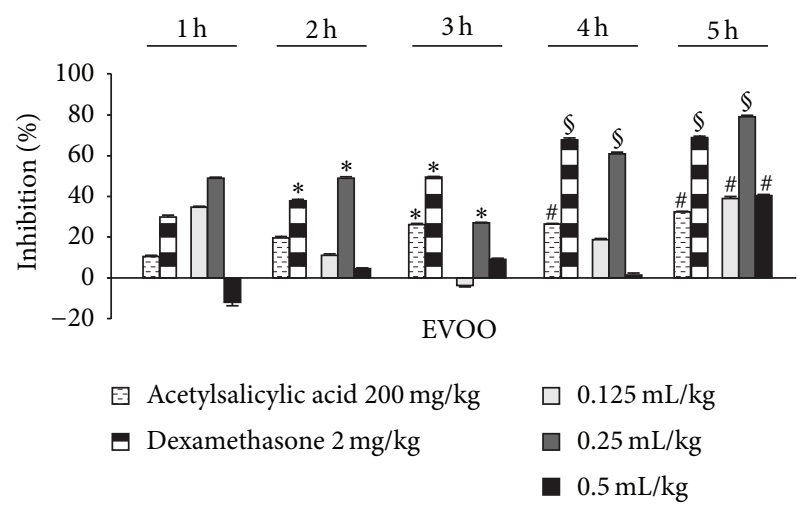

(b)

FIGURE 2: Anti-inflammatory effect of extra virgin olive oil. (a) Time course of the carrageenan-induced rat hind paw edema volume after intraplantar injection of acetylsalicylic acid $(200 \mathrm{mg} / \mathrm{kg})$, dexamethasone $(2 \mathrm{mg} / \mathrm{kg}$ ) and extra virgin olive oil (resp. 0.125, 0.25, and $0.5 \mathrm{~mL} / \mathrm{kg}$ ). Dexamethasone and acetylsalicylic acid were used as reference agents while saline was used as control. (b) Percentage of carrageenan-induced edema inhibition by extra virgin olive oil and reference agents as compared to saline-treated rats. Results are reported as means $\pm \mathrm{SD} .{ }^{*} P<0.05,{ }^{\#} P<0.01$, and ${ }^{\S} P<$ 0.001 (two-tailed Student's $t$-test), as compared to saline-treated rats.

the well-established acute inflammatory models in vivo. The intraplantar injection of $100 \mu \mathrm{L}$ of carrageenan (0.6\%) into the rat's hind paw induced progressive increasing edema volume in the control group (Figure 2(a)) as inflammatory response as early as $0-5$ hours. Pretreatment with EVOO at different doses of $0.125,0.25$, and $0.5 \mathrm{~mL} / \mathrm{kg}$ caused a significant inhibition of the paw swelling caused by carrageenan after $4 \mathrm{~h}$. EVOO $0.25 \mathrm{~mL} / \mathrm{kg}$ exhibited maximum inhibition of $79 \%$ at the 5 th hour of the experiment. Under the same experimental conditions, the anti-inflammatory effect of dexamethasone as well as ASA was equivalent, respectively, to 69 and $32 \%$ inhibition. At both doses 0.125 and $0.5 \mathrm{~mL} / \mathrm{kg}$ the EVOO effect is less intense than the positive control though it remains significantly protective about $40 \%$, which seemed to be more

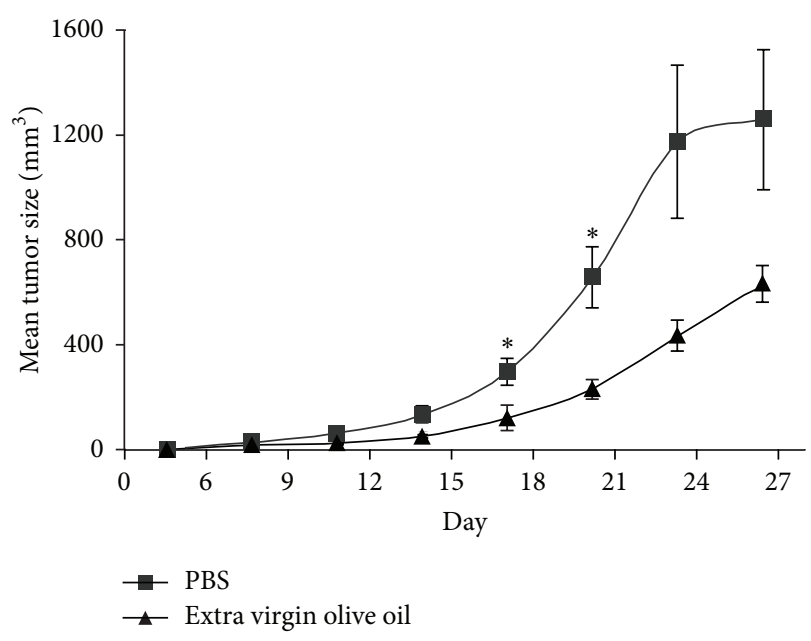

FIGURE 3: In vivo growth inhibitory effects of extra virgin olive oil on HCT 116 human colon cancer cells. HCT 116 cells were injected subcutaneously into athymic mice (10 mice for EVOO-treated groups and 10 mice for PBS-treated controls), and one-week later $200 \mu \mathrm{L}$ intraperitoneal injections of PBS 1X or extra virgin olive oil $(1 \mathrm{~mL} / \mathrm{kg})$ were performed, as described in Materials and Methods. Tumor size was then routinely monitored by means of a common caliper. Results are reported as means $\pm \mathrm{SD}$. ${ }^{*} P<0.05$ (two-tailed Student's $t$-test), as compared to PBS-treated mice.

effective than ASA at the fifth hour (Figure 2(b)). We noted that at, $0.5 \mathrm{~mL} / \mathrm{kg}$, EVOO shows a proinflammatory value at $(1 \mathrm{~h})$ and presents an ascendant curve with an extreme value similar to the negative control group at $(4 \mathrm{~h})$. Nevertheless, this dose of EVOO reaches the $40 \%$ of edema inhibition at the last hour $(5 \mathrm{~h})$ of the experiment. This phenomenon appeared to be related to the volume of injection $(100 \mu \mathrm{L}$ of oil) in the subplantar space of the hind paw, presumably relatively tight, that consequently seems to create a sort of tangible volume miming a proinflammatory effect. Hence, the inhibition percent of this dose could not refer to the plausible anti-inflammatory effect which is probably more important (Figure 2(b)). As a summary, these results are conclusive of the potent anti-inflammatory activity of EVOO in acute inflammation.

3.3. In Vivo Anticolon Cancer Effect of Extra Virgin Olive Oil. We evaluated the anti cancer efficacy of EVOO in vivo. About $2 \times 10^{5}$ HCT 116 WT cells were implanted in Athymic nu/nu mice subcutaneously. After that each mouse had a tumor of about $125 \mathrm{~mm}^{3}$, three times a week intraperitoneal injection of phosphate-buffered saline X1 (PBS) or EVOO $(4 \mathrm{~mL} / \mathrm{kg}$ ) started. Our results show that EVOO treatment significantly inhibited the growth of colon tumors (Figure 3). Starting to third week of treatment, tumor volume in the treated group was approximately reduced by $50 \%$ as compared with control group. These data demonstrate that EVOO has a great tumor growth inhibition effect. During the whole treatment period, no significant weight changes or macroscopic signs of toxicity occurred in the treated animals suggesting that the intraperitoneal administration of EVOO was well tolerated. 


\section{Discussion}

In this study, we report that the administration of EVOO have a strong analgesic and anti-inflammatory effect. The antinociception effect of EVOO was obviously noticed via two nociception models. First, the acetic acid-induced writhing as characteristic abdominal stretching and extension of hindlimbs [18] to screen for both central and peripheral analgesic activity. In fact, the presence of acetic acid provokes the release of endogenous mediators like bradykinin, substance $\mathrm{P}$, prostaglandins, and some cytokines which excite chemosensitive nociceptors thus far results pain $[19,20]$. Second, formalin-induced licking/biting and shaking paw in mice was conducted to distinguish analgesic from antiinflammatory properties, where the early phase is characterized by neurogenic pain due to a direct effect on nociceptors resulting from bradekinin and substance $\mathrm{P}$ release, whereas the late phase is characterized by inflammatory pain response of inflammatory mediators, namely, histamine and prostaglandins liberation $[14,15,19]$. Formalin injection provokes a direct and characteristic response of nociceptors leading to stimulation of C fibers [21]. It should be mentioned that endogenous inflammatory pain-producing substances can act in a synergistic way to increase pain levels [22]. Such chemical nociceptive stimuli induced by formalin or acetic acid entail endogenous pronociceptive substances (bradekinin and prostanoids) release, which explains the characteristic behavior resulting from nociception response in mice $[15,23]$. EVOO as well as ASA exhibited antinociceptive activity in abdominal constriction test (Figure 1(a)), defining blockade of peripherally and centrally mediated nociception induced by chemical stimuli. This effect on nociception process was further confirmed by the drastic effectiveness of EVOO in attenuating the early phase of formalin test and late phase with a lower but significant effect (Figures 1(b) and 1(c)). The finding that EVOO as Morphine exerted marked analgesic activity in the late phase of the formalin test suggests an effect on acute inflammation. Results from the carrageenan-induced paw edema confirm this suggestion. The carrageenan-induced inflammatory response presents two main phases: the initial phase lasts up to $2 \mathrm{~h}$ involving histamine, serotonin (5-HT), and bradekinin as for the second phase, it lasts from 3 to $5 \mathrm{~h}$ and is mediated by prostaglandins and cyclooxygenases $[24,25]$. EVOO antiinflammatory effect seems to be due to the inhibition of the cyclooxygenases enzymes release which is involved in prostaglandins synthesis [26]. The anti-inflammatory activity of EVOO shown to be potent was tested in acute and subacute inflammation models that are, respectively, formalin test (late phase) and the carrageenan-induced paw edema subsequently (Figures 1(b), 1(c), and 2). The latter test used ASA (NSAID) and dexamethasone (steroidal drug) as [21] and presents two major phases of serotonin and histamine release succeeded by accelerating paw swelling due to prostaglandins lysosomes and bradekinins [24, 25, 27]. EVOO elicits more evident effect on cyclooxygenases pathway, consequently prostaglandins inhibition [26].

The benefic, analgesic, and anti-inflammatory effect of EVOO is due to its composition, which is quit complex.
Indeed EVOO can be divided into two groups namely saponifiable (about $99 \%$ of the oil) and unsaponifiable fractions. The saponifiable fraction includes fatty acids and triacylglycerols while the unsaponifiable fractions include squalene, carotenoids, chlorophylls, tocopherols, aliphatic alcohols, sterols, phenolic compounds, and volatile compounds [28]. The groups of minor compounds, especially polyphenol and triterpenes, are reported to possess active analgesic and anti-inflammatory effect. The oleuropein aglycone, a phenolic compound of EVOO, is described to have a great anti-inflammatory effect with the same experimental model as our study, meaning the carrageenan-induced [29] and also in vitro effect by preventing the stimulatory effect of TNF- $\alpha$ on human monocyte-like cell line [30]. Moreover, tyrosol and hydroxytyrosol, bioactive metabolites of oleuropein, were shown to have an anti-inflammatory action in vivo with an ovariectomy/inflammation experimental model [31]. Similarly, oleocanthal (other phenolic compound) was found to display nonsteroidal anti-inflammatory drug activity "ibuprofen like." Ibuprofen is widely used in the therapeutic management of joint inflammatory diseases [32] and has a strong analgesic effect [33]. Recently, it has been shown that another minor compound of EVOO, the maslinic acid, a pentacyclic triterpenoid, has a broader antinociceptive effect than ibuprofen via the acetic acid-induced writhing and formalin test [34]. Erythrodiol (triterpenes alcohols) and oleanolic acid (triterpenes acid) have also shown antiinflammatory activity reported in vitro studies [35].

The last part of our study was the investigation of EVOO activity in a colon cancer xenograft model assessment and showed a significant and promising inhibition of the tumor (Figure 3). It has been demonstrated that treatment of human colon adenocarcinoma cells with phenolic compounds resulted in the inhibition of all colon carcinogenetic processes such as initiation, promotion, and metastasis, triggering cell death by apoptosis $[36,37]$.

We should note at the end that about $97 \%$ of the main phenolic compounds of the EVOO are secoiridoids [38] and the free secoiridoids are able to cross the oil/water barrier [39] confirming the choice of the in vivo model for this study.

This study constitutes a starting data and model for a future investigation of the different Mediterranean extra virgin olive oil. In fact, due to importance of the environment, culture condition, and soil to the final composition of the oil, difference exists between inter/intraregion EVOO compounds. On the other context, due to the benefic effect of the oil, we can propose the EVOO as an adjuvant, vehicle, or emulsion in a treatment context and have a synergistic effect [40] or to prevent undesired effects of other used lipids [41].

\section{Conclusion}

In conclusion, the present study shows that EVOO presents a marked analgesic, anti-inflammatory, and anticancer activity confirming its beneficial properties and supports its use in traditional and self-medication. 


\section{Abbreviations}

ASA: Acetylsalicylic acid

CVD: Cardiovascular diseases

EVOO: Extra virgin olive oil

NSAID: Nonsteroidal anti-inflammatory drug

PBS: $\quad$ Phosphate-buffered saline.

\section{Conflict of Interests}

The authors declare that they have no conflict of interests.

\section{Author's Contribution}

Myriam Fezai designed and performed experiments, analyzed data, and drafted the paper; Laura Senovilla performed experiments and analyzed data; Mohamed Jemaà designed and performed experiments, analyzed data, and drafted the paper; Mossadok Ben-Attia designed experiments and directed biological studies. Mohamed Jemaà and Mossadok Ben-Attia share senior coauthorship.

\section{Acknowledgments}

The authors are indebted to Bert Vogelstein for human colon carcinoma HCT 116 cells, Guido Kroemer for the anticancer experiments facility, and Ilio Vitale for the critical reading of the paper.

\section{References}

[1] W. C. Willett, F. Sacks, A. Trichopoulou et al., "Mediterranean diet pyramid: a cultural model for healthy eating," American Journal of Clinical Nutrition, vol. 61, no. 6, pp. 1402S-1406S, 1995.

[2] N. Kontou, T. Psaltopoulou, D. Panagiotakos, M. A. Dimopoulos, and A. Linos, "The mediterranean diet in cancer prevention: a review," Journal of Medicinal Food, vol. 14, no. 10, pp. 10651078, 2011.

[3] E. M. Berry, Y. Arnoni, and M. Aviram, "The Middle Eastern and biblical origins of the Mediterranean diet," Public Health Nutrition, vol. 14, no. 12A, pp. 2288-2295, 2011.

[4] K. L. Tuck and P. J. Hayball, "Major phenolic compounds in olive oil: metabolism and health effects," Journal of Nutritional Biochemistry, vol. 13, no. 11, pp. 636-644, 2002.

[5] H. F. Al-Azzawie and M.-S. S. Alhamdani, "Hypoglycemic and antioxidant effect of oleuropein in alloxan-diabetic rabbits," Life Sciences, vol. 78, no. 12, pp. 1371-1377, 2006.

[6] H. Karaosmanoglu, F. Soyer, B. Ozen, and F. Tokatli, "Antimicrobial and antioxidant activities of turkish extra virgin olive oils," Journal of Agricultural and Food Chemistry, vol. 58, no. 14, pp. 8238-8245, 2010.

[7] R. De la Puerta, E. Martinez-Dominguez, and V. RuizGutierrez, "Effect of minor components of virgin olive oil on topical antiinflammatory assays," Zeitschrift fur Naturforschung C, vol. 55, no. 9-10, pp. 814-819, 2000.

[8] M. Ruiz-Canela and M. A. Martínez-González, "Olive oil in the primary prevention of cardiovascular disease," Maturitas, vol. 68, no. 3, pp. 245-250, 2011.
[9] F. J. Kok and D. Kromhout, "Atherosclerosis: epidemiological studies on the health effects of a Mediterranean diet," European Journal of Nutrition, vol. 43, no. 1, pp. I/2-I/5, 2004.

[10] C. Pelucchi, C. Bosetti, E. Negri, L. Lipworth, and C. la Vecchia, "Olive oil and cancer risk: an update of epidemiological findings through 2010," Current Pharmaceutical Design, vol. 17, no. 8, pp. 805-812, 2011.

[11] S. Vasto, C. Rizzo, and C. Caruso, "Centenarians and diet: what they eat in the Western part of Sicily," Immunity \& Ageing, vol. 9, article 10, 2012.

[12] M. Guerfel, M. Ben Mansour, Y. Ouni, F. Guido, D. Boujnah, and M. Zarrouk, "Triacylglycerols composition and volatile compounds of virgin olive oil from Chemlali cultivar: comparison among different planting densities," ScientificWorldJournal, vol. 2012, Article ID 354019, 6 pages, 2012.

[13] H. O. Collier, L. C. Dinneen, C. A. Johnson, and C. Schneider, "The abdominal constriction response and its suppression by analgesic drugs in the mouse," British Journal of Pharmacology, vol. 32, no. 2, pp. 295-310, 1968.

[14] S. Hunskaar and K. Hole, "The formalin test in mice: dissociation between inflammatory and non-inflammatory pain," Pain, vol. 30, no. 1, pp. 103-114, 1987.

[15] K. Nakamoto, T. Nishinaka, M. Mankura, W. Fujita-Hamabe, and S. Tokuyama, "Antinociceptive effects of docosahexaenoic acid against various pain stimuli in mice," Biological and Pharmaceutical Bulletin, vol. 33, no. 6, pp. 1070-1072, 2010.

[16] C. A. Winter, E. A. Risley, and G. W. Nuss, "Carrageenininduced edema in hind paw of the rat as an assay for antiiflammatory drugs," Proceedings of the Society for Experimental Biology and Medicine, vol. 111, pp. 544-547, 1962.

[17] M. Jemaa, I. Vitale, O. Kepp et al., "Selective killing of p53deficient cancer cells by SP600125," EMBO Molecular Medicine, vol. 4, no. 6, pp. 500-514, 2012.

[18] A. Bedini, M. Baiula, L. Gentilucci, A. Tolomelli, R. De Marco, and S. Spampinato, "Peripheral antinociceptive effects of the cyclic endomorphin-1 analog c[YpwFG] in a mouse visceral pain model," Peptides, vol. 31, no. 11, pp. 2135-2140, 2010.

[19] B. G. Pinheiro, A. S. B. Silva, G. E. P. Souza et al., "Chemical composition, antinociceptive and anti-inflammatory effects in rodents of the essential oil of Peperomia serpens (Sw.) Loud," Journal of Ethnopharmacology, vol. 138, no. 2, pp. 479-486, 2011.

[20] Y. Ye, Y. Guo, and Y. T. Luo, "Anti-inflammatory and analgesic activities of a novel biflavonoid from shells of Camellia oleifera," International Journal of Molecular Sciences, vol. 13, no. 10, pp. 12401-12411, 2012.

[21] M. Shibata, T. Ohkubo, H. Takahashi, and R. Inoki, "Modified formalin test: characteristic biphasic pain response," Pain, vol. 38, no. 3, pp. 347-352, 1989.

[22] C. R. McCurdy and S. S. Scully, "Analgesic substances derived from natural products (natureceuticals)," Life Sciences, vol. 78, no. 5, pp. 476-484, 2005.

[23] T. Ali, M. Javan, A. Sonboli, and S. Semnanian, "Evaluation of the antinociceptive and anti-inflammatory effects of essential oil of Nepeta pogonosperma Jamzad et Assadi in rats," Daru, vol. 20, no. 1, article 48, 2012.

[24] M. Di Rosa, J. P. Giroud, and D. A. Willoughby, "Studies on the mediators of the acute inflammatory response induced in rats in different sites by carrageenan and turpentine," Journal of Pathology, vol. 104, no. 1, pp. 15-29, 1971. 
[25] K. R. Riella, R. R. Marinho, J. S. Santos et al., "Anti-inflammatory and cicatrizing activities of thymol, a monoterpene of the essential oil from Lippia gracilis, in rodents," Journal of Ethnopharmacology, vol. 143, no. 2, pp. 656-663, 2012.

[26] N. P. Babu, P. Pandikumar, and S. Ignacimuthu, "Anti-inflammatory activity of Albizia lebbeck Benth., an ethnomedicinal plant, in acute and chronic animal models of inflammation," Journal of Ethnopharmacology, vol. 125, no. 2, pp. 356-360, 2009.

[27] G. Amresh, G. D. Reddy, C. V. Rao, and P. N. Singh, "Evaluation of anti-inflammatory activity of Cissampelos pareira root in rats," Journal of Ethnopharmacology, vol. 110, no. 3, pp. 526-531, 2007.

[28] C. Alarcón de la Lastra, M. D. Barranco, V. Motilva, and J. M. Herrerías, "Mediterranean diet and health: biological importance of olive oil," Current Pharmaceutical Design, vol. 7, no. 10, pp. 933-950, 2001.

[29] D. Impellizzeri, E. Esposito, E. Mazzon et al., "The effects of oleuropein aglycone, an olive oil compound, in a mouse model of carrageenan-induced pleurisy," Clinical Nutrition, vol. 30, no. 4, pp. 533-540, 2011.

[30] M. D. Agli, R. Fagnani, G. V. Galli et al., "Olive oil phenols modulate the expression of metalloproteinase 9 in THP-1 cells by acting on nuclear factor-kappaB Signaling," Journal of Agricultural and Food Chemistry, vol. 58, no. 4, pp. 2246-2252, 2010.

[31] C. Puel, J. Mardon, A. Agalias et al., "Major phenolic compounds in olive oil modulate bone loss in an ovariectomy/ inflammation experimental model," Journal of Agricultural and Food Chemistry, vol. 56, no. 20, pp. 9417-9422, 2008.

[32] G. K. Beauchamp, R. S. J. Keast, D. Morel et al., "Ibuprofen-like activity in extra-virgin olive oil," Nature, vol. 437, no. 7055, pp. 45-46, 2005.

[33] C. E. Argoff, "Topical analgesics in the management of acute and chronic pain," Mayo Clinic Proceedings, vol. 88, no. 2, pp. 195-205, 2013.

[34] F. R. Nieto, E. J. Cobos, J. M. Entrena, A. Parra, A. GarciaGranados, and J. M. Baeyens, "Antiallodynic and analgesic effects of maslinic acid, a pentacyclic triterpenoid from Olea europaea," Journal of Natural Products, vol. 76, no. 4, pp. 737740, 2013.

[35] R. Rodríguez-Rodríguez, M. D. Herrera, J. S. Perona, and V. Ruiz-Gutiérrez, "Potential vasorelaxant effects of oleanolic acid and erythrodiol, two triterpenoids contained in "orujo" olive oil, on rat aorta," British Journal of Nutrition, vol. 92, no. 4, pp. 635642, 2004.

[36] C. I. R. Gill, A. Boyd, E. McDermott et al., "Potential anti-cancer effects of virgin olive oil phenols on colorectal carcinogenesis models in vitro," International Journal of Cancer, vol. 117, no. 1 , pp. 1-7, 2005.

[37] Y. Z. H.-Y. Hashim, I. R. Rowland, H. McGlynn et al., "Inhibitory effects of olive oil phenolics on invasion in human colon adenocarcinoma cells in vitro," International Journal of Cancer, vol. 122, no. 3, pp. 495-500, 2008.

[38] A. Vazquez-Martin, S. Fernández-Arroyo, S. Cufí et al., "Phenolic secoiridoids in extra virgin olive oil impede fibrogenic and oncogenic epithelial-to-mesenchymal transition: extra virgin olive oil as a source of novel antiaging phytochemicals," Rejuvenation Research, vol. 15, no. 1, pp. 3-21, 2012.

[39] R. W. Owen, A. Giacosa, W. E. Hull et al., "Olive-oil consumption and health: the possible role of antioxidants," The Lancet Oncology, vol. 1, no. 2, pp. 107-112, 2000.

[40] J. P. de la Cruz, S. del Río, J. A. López-Villodres, M. A. Villalobos, N. Jebrouni, and J. A. González-Correa, "Virgin olive oil administration improves the effect of aspirin on retinal vascular pattern in experimental diabetes mellitus," British Journal of Nutrition, vol. 104, no. 4, pp. 560-565, 2010.

[41] P. Onar, B. D. Yildiz, E. A. Yildiz, T. Besler, and O. Abbasoglu, "Olive oil-based fat emulsion versus soy oil-based fat emulsion in abdominal oncologic surgery," Nutrition in Clinical Practice, vol. 26, no. 1, pp. 61-65, 2011. 

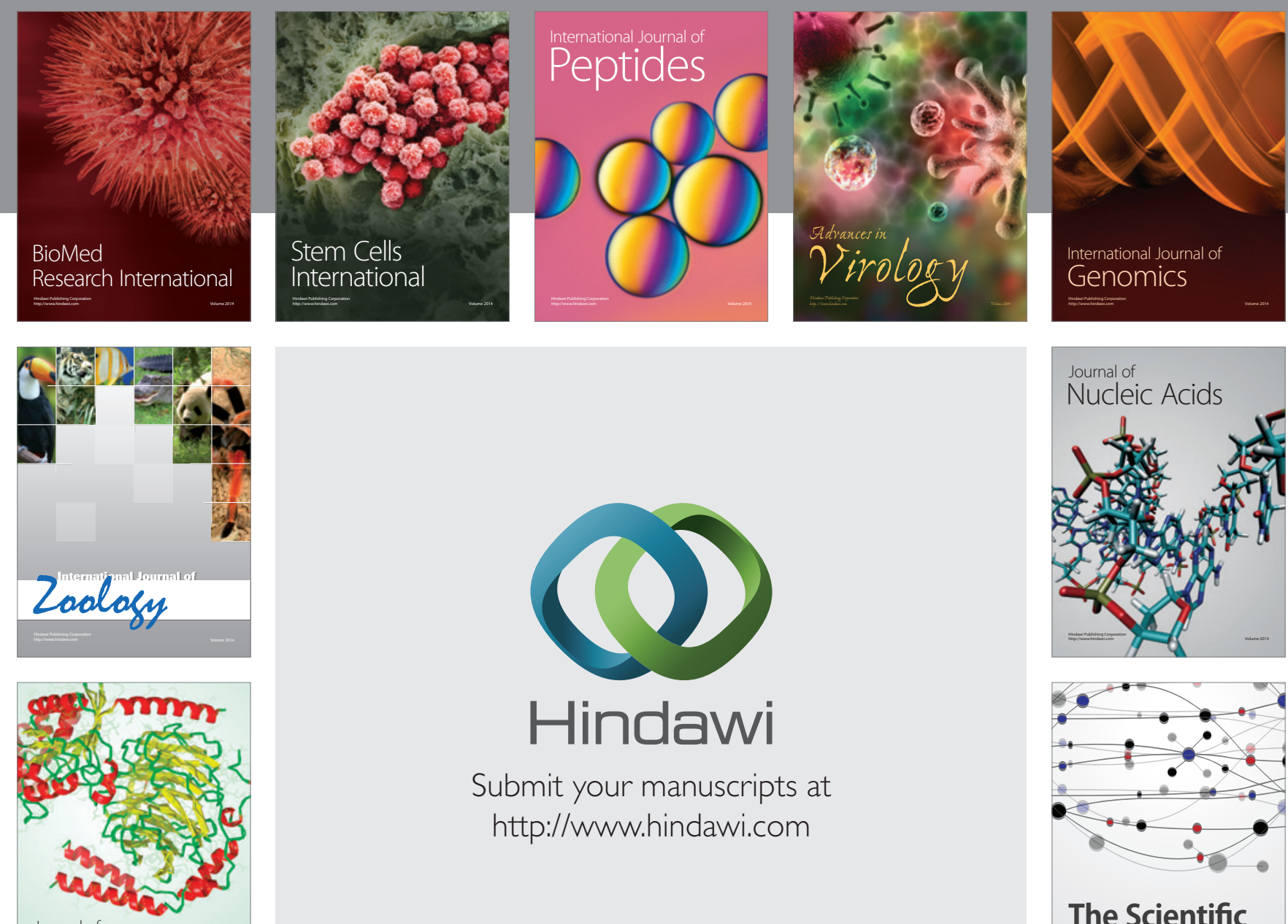

Submit your manuscripts at

http://www.hindawi.com

Journal of
Signal Transduction
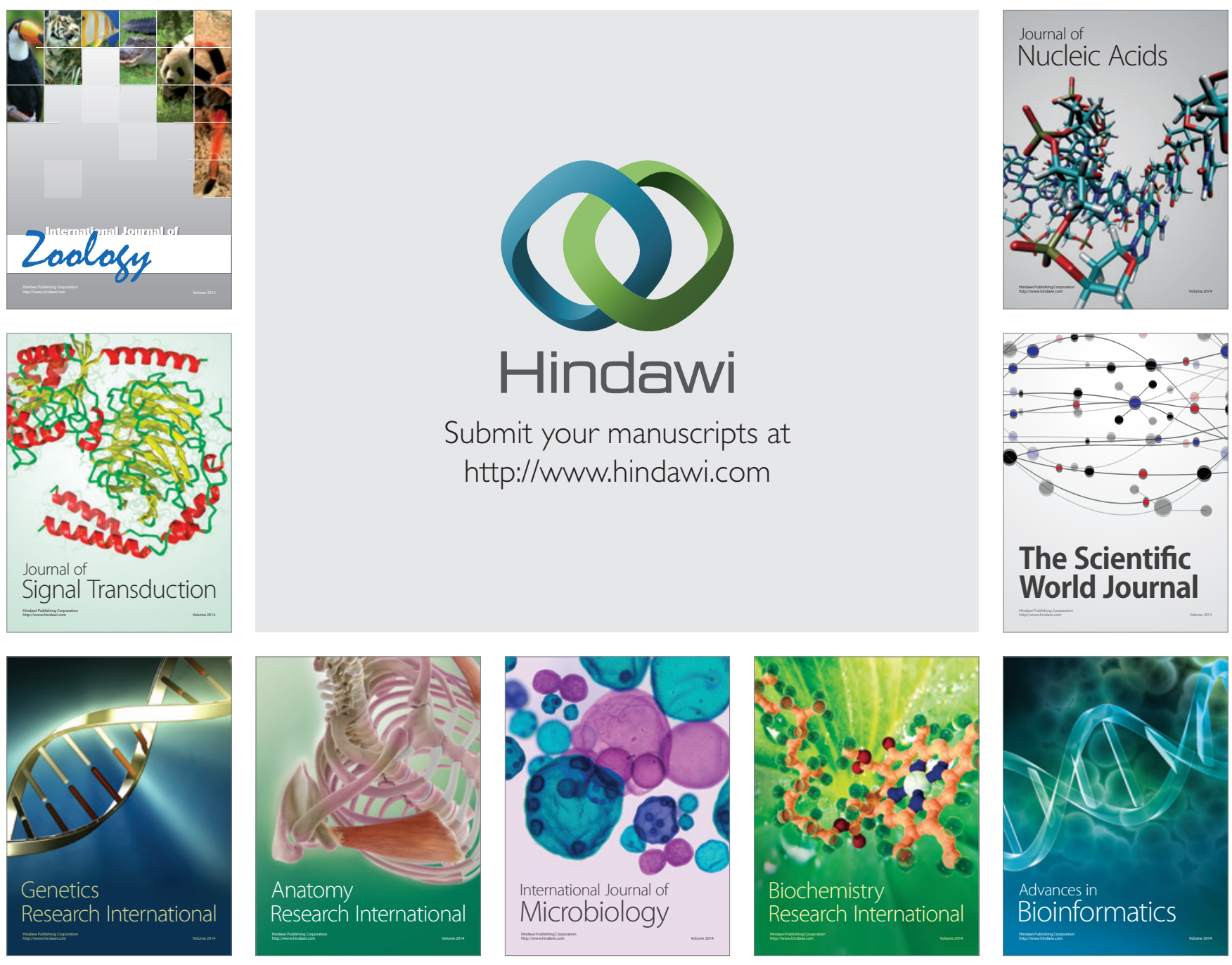

The Scientific World Journal
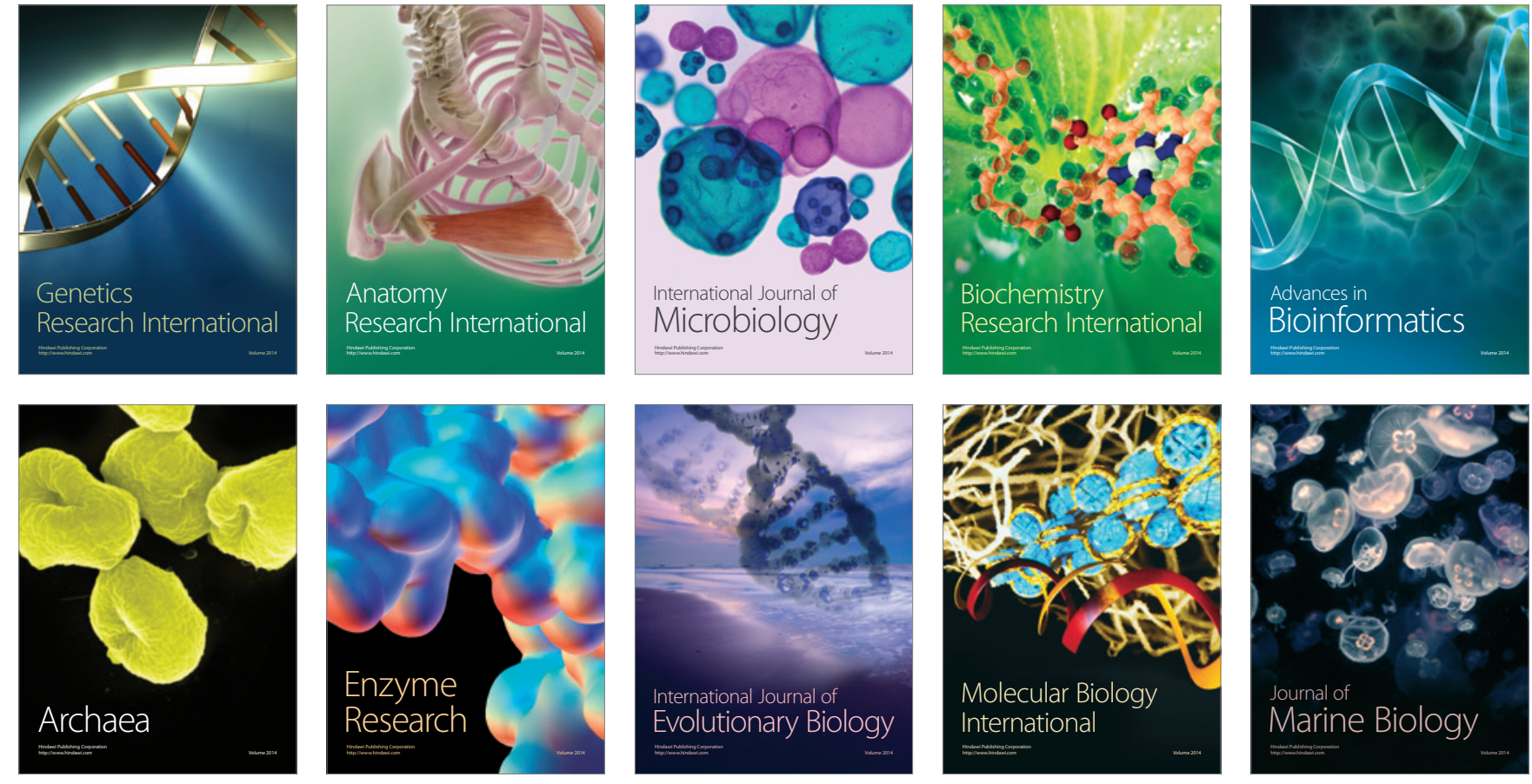